\title{
EXPERIMENTAL INVESTIGATION OF STALL AND SURGE IN A MULTISTAGE COMPRESSOR
}

\author{
Enrico Munari ${ }^{1}$, Mirko Morini $^{2}$, Michele Pinelli ${ }^{1}$, Pier Ruggero Spina ${ }^{1}$, Alessio Suman ${ }^{1}$ \\ 1 Dipartimento di Ingegneria, Università degli Studi di Ferrara, Ferrara, Italy \\ 2 Dipartimento di Ingegneria Industriale, Università degli Studi di Parma, Parma, Italy
}

\begin{abstract}
Flow instability conditions, in particular during surge and stall phenomena, have always influenced the operational reliability of turbo-compressors and have attracted significant interest resulting in extensive literature. Nowadays, this subject is still one of the most investigated because of its high relevance on centrifugal and axial compressor operating flow range, performance and efficiency. Many researchers approach this important issue by developing numerical models, whereas others approach it through experimental studies specifically carried out in order to better comprehend this phenomenon. The aim of this paper is to experimentally analyze the stable and unstable operating conditions of an aeronautic turbo-shaft gas turbine axial-centrifugal compressor installed on a brand new test-rig properly designed for this purpose.

The test facility is set up in order to obtain i) the compressor performance maps at rotational speeds up to 25,000 rpm and ii) the compressor transient behavior during surge. By using two different test rig layouts, instabilities occurring in the compressor, beyond the peak of the characteristic curve, are identified and investigated

These two types of analysis are carried out thanks to pressure, temperature and mass flow sensors located in strategic positions along the circuit. These measurement sensors are part of a proper control and acquisition system, characterized by an adjustable sampling frequency. Thus, the desired operating conditions of the compressor, in terms of mass flow and rotational speed and transient of these two parameters are regulated by this dedicated control system.
\end{abstract}

\section{INTRODUCTION}

The experimental analysis of compressor performance is one of the essential factors in the turbomachinery sector, not only because it ensures the reliability of a machine but also because it shows the limits of its operating range and its critical working conditions. It is also undeniable that these data are helpful for giving guidance for improving the designs of actual dynamic compressors and gas turbines.

One of the crucial test field analyses is the evaluation of off-design conditions and flow instability phenomena. This allows the turbomachine dynamic behavior to be examined and predicted, which is nowadays one of the main issues investigated by researchers. The two main instabilities which can occur on compressors, due to an excessive reduction of mass flow rate, are rotating stall and surge. Both of them cause a rapid change in the flow pattern in the compressor.

Rotating stall is a flow instability which develops circumferentially through rotating "stalled" cells around the annulus which sometimes can extend along the entire longitudinal dimension of the machine. These cells rotate, from a fixed observer point of view, in the same direction as the rotor but with a lower rotational speed, although in literature there is experimental evidence of backwards traveling rotating waves [1]. Rotating stall can be classified in two categories: progressive stall and abrupt stall [2]. The first is distinguished by a change in noise of the compressor and by a slight decrease in the pressure rise and the flow rate while the second is characterized by a drastic drop in performance, especially for axial compressors. During rotating stall the average mass flow rate through the compressor is constant, but the flow velocity varies locally.

Surge is instead an axisymmetric phenomenon and leads to a variable time averaged mass flow rate. The frequency of this variation depends on the storage volume, thus on its filling and emptying time. This phenomenon can occur as mild surge, when the operating point orbits around the peak of the characteristic curve; as classic surge, when the pressure ratio and mass flow oscillations become highly unstable; or as deep surge when it generates a back flow ([2-4]). The occurrence of surge depends on the characteristics of the compression system as explained below. 
These two types of instabilities must obviously be avoided, in particular surge, because during its transients it can also lead to structural damage of rotor blades caused by stresses, fluttering and/or vibrations which are critical for their integrity.

Since the study of Emmons et al. [5] who first give a description of the local mechanism of rotating stall, the significance of this topic has led to many interesting studies such as that of Greitzer [6]. He developed a non-linear model to predict the transient behavior of an axial compressor subjected to an initial perturbation. In [6], the non-dimensional system parameter

$$
B=\frac{U}{2 a} \sqrt{\frac{V_{\mathrm{p}}}{A_{\mathrm{c}} L_{\mathrm{c}}}}
$$

was also identified in order to establish the occurrence of surge. This parameter shows dependency not only on the rotational velocity of the compressor but also on the geometric characteristics and size of the compression system. Greitzer demonstrated that transitory behavior of a compressor, installed in a given compression system, depends on the value of $\mathrm{B}$, in addition to the profile of the characteristic curve. He stated that there is a critical value of $\mathrm{B}$ (in that case equal to 0.8 ) which defines the type of instability which the compressor would experience beyond the peak of its characteristic curve. For higher values, the compressor would experience surge whereas for lower ones it would go into stall (the operating point moves to the stalled curve).

Later, another very successful model was presented by Moore and Greitzer [7]. This model, and its approach, have been successively used and implemented by many authors such as in [8] for studying post-stall behavior in compressors.

Despite many attempts to theoretically describe the transitory behavior in detail, experimental tests are still necessary in order to better comprehend the dynamic correlations between the critical performance parameters, especially during stall and surge. These data are crucially important because they can be used for the comparison and validation of numerical models [9]. Moreover, they can also assist in the creation of reliable and robust surge and stall avoidance or control systems. Different techniques to avoid and control these flow instabilities are reported in literature [10-13].

This publication aims to contribute to the understanding of the surge phenomenon and its inception mechanism by acquiring experimental data from a test rig built at the University of Ferrara. The paper presents reliable data regarding stall and surge in a high speed multistage axialcentrifugal compressor. The compressor performance was analyzed during stable and transient operating conditions.

The new facility replaces the previous ones described in [14-16] and it is dedicated to the study of unstable working conditions, in particular surge and stall phenomena. The test rig is located inside an acoustic/soundproofed chamber and is characterized by i) a new support frame for the compressor which allows a safe environment for off-design tests, ii) a new gear train, installed to achieve higher rotational speeds and consuming less power, iii) new instrumented sensors, some of them specifically chosen for studying flow instabilities, and iv) a new upstream and downstream compressor piping system with solenoid throttling valves. Moreover, a new dedicated data acquisition and processing system is integrated on the facility by simultaneously using the NI cDAQ 9174 and NI SCXI 1000 together with the software LabView.

The paper shows the results of two different types of tests. Basically, the experiments were carried out with two different compression systems. A first series of tests was performed with a throttle valve immediately downstream of the compressor in order to obtain the steady state performance maps at different rotational speeds (up to 25,000 rpm). The second series of tests was carried out with a plenum volume placed between the compressor and the throttle valve in order to allow the onset of surge while the mass flow rate is reduced.

The test field data are analyzed showing the performance of the turbomachinery and its transient behavior towards and during surge.

\section{NOMENCLATURE}

\begin{tabular}{|c|c|c|}
\hline$A$ & \multicolumn{2}{|c|}{ flow-through area } \\
\hline$a$ & \multicolumn{2}{|c|}{ speed of sound } \\
\hline$B$ & \multicolumn{2}{|c|}{ dimensionless number described in eq (1) } \\
\hline$c$ & \multicolumn{2}{|c|}{ number of acquisition channels } \\
\hline$f$ & \multicolumn{2}{|c|}{ frequency } \\
\hline$L$ & \multicolumn{2}{|c|}{ effective length } \\
\hline$M$ & \multicolumn{2}{|c|}{ torque } \\
\hline$m$ & \multicolumn{2}{|c|}{ mass flow rate } \\
\hline$N$ & \multicolumn{2}{|c|}{ rotational speed } \\
\hline$P$ & \multicolumn{2}{|c|}{ power } \\
\hline$p$ & \multicolumn{2}{|l|}{ pressure } \\
\hline$R H$ & \multicolumn{2}{|c|}{ relative humidity } \\
\hline$T$ & \multicolumn{2}{|c|}{ temperature } \\
\hline$U$ & \multicolumn{2}{|c|}{ mean rotor velocity } \\
\hline$V$ & \multicolumn{2}{|c|}{ volume } \\
\hline$\alpha$ & \multicolumn{2}{|c|}{ throttling valve position } \\
\hline$\beta$ & \multicolumn{2}{|c|}{ pressure ratio } \\
\hline$\Delta p$ & \multicolumn{2}{|c|}{ relative pressure } \\
\hline & $p_{0}$ & non-dimensional pressure \\
\hline$\gamma$ & \multicolumn{2}{|c|}{$p_{0, \text { ref }} \quad$ parameter } \\
\hline$\eta$ & \multicolumn{2}{|c|}{ efficiency } \\
\hline 9 & \multicolumn{2}{|r|}{ non-dimensional temperature } \\
\hline & \multicolumn{2}{|l|}{$\overline{T_{0, \text { ref }}}$} \\
\hline$\mu$ & $m \sqrt{\theta}$ & non-dimensional corrected mass \\
\hline & \multicolumn{2}{|l|}{$\begin{array}{l}\gamma \\
\text { gear ratio }\end{array}$} \\
\hline$\tau$ & \\
\hline$v$ & $\frac{N_{\mathrm{c}}}{\sqrt{\vartheta}}$ & corrected rotational speed \\
\hline
\end{tabular}

\section{Subscript and Superscript}

\begin{tabular}{ll}
\hline 0 & stagnation physical quantity \\
$1,2,3$ & test rig sections and segments \\
$\mathrm{amb}$ & ambient conditions \\
$\mathrm{c}$ & compressor
\end{tabular}




$\begin{array}{ll}\text { cDAQ } & \text { NI Compact DAQ } \\ \text { el } & \text { electric quantity } \\ \text { mot } & \text { electric motor } \\ \text { max } & \text { maximum } \\ \text { min } & \text { minimum } \\ \text { mod1 } & \text { module } 1 \\ \text { mod2 } & \text { module } 2 \\ \text { norm } & \text { normalized } \\ \text { PTFE } & \text { Polytetrafluoroethylene } \\ \text { p } & \text { plenum } \\ \text { is } & \text { isentropic } \\ \text { ref } & \text { reference conditions } \\ \text { stage5 } & \text { section at fifth axial stage }\end{array}$

\section{LITERATURE REVIEW}

The difficulty of experimentally approaching stall and surge comes from different aspects: i) the need of reliable and accurate dynamic measurement sensors, ii) the problematic positioning of these sensors at the most significant locations in the system, and iii) the requirement of a suitable control and acquisition system because of the necessity of reliable time dependent information. As stated in [17], pressure measurements are generally used to analyze unsteady phenomena. However, only a few works with a very high sampling frequency, or high temporal resolution such as greater or above $100 \mathrm{kHz}$, were presented. The sampling frequency is fundamental not only to detect disturbances which produce and lead to instability when approaching surge, but also to prevent aliasing errors and better define the amplitudes of these perturbations.

To recap, when an experimental study on stall and surge is carried out, the first main requirement is the appropriate design of a test rig dedicated to the investigation of critical working conditions. All the considerations stated above are a direct cause of the high cost for these types of experimental campaigns. Therefore, the tendency is to obtain the dynamic operational information by testing small scale compressors, leading to a smaller and less complex test bench.

Although stall and surge, and their inception, are clearly two distinct phenomena, and their consequences have a considerably different impact on the compressor, it is not always easy to study one without taking into consideration the other and vice versa. This literature review tries to keep separate, as much as possible, the works carried out for stall analysis from those dedicated to surge but, in some parts, the cited works inevitably connect these two themes.

Experimental investigations have been conducted by many authors in order to evaluate compressor behavior under transient conditions while also trying to identify the stall and surge onset. The first significant representation of the dynamic behavior of a compressor during surge and stall was given by Greitzer [6, 18]. In [18] he studied a three stage axial flow compressor recognizing and describing, through the analysis of data, the compressor response to stall, classic surge and deep surge. Successively, the work of Camp and Day [19] gave a description of which type of disturbance can occur before stall on high and low speed compressors, formulating a simple descriptive model to define when modal oscillations occur rather than spike instability. Spakovszky and Roduner [20] found this theory consistent, analyzing the performance curves of centrifugal compressor vaned diffuser subcomponents. They confirmed the influence of the loading and matching of the subcomponents on the disturbance type of stall inception. Day and Freeman [21] discovered that spike, which causes stall inception, increases rapidly until it generates a rotating stall cell caused by the abrupt transition of flow. Another type of approach which proved to be effective in the detection of stall is vibro-acoustic analysis. Morini et al. [14] conducted a vibroacoustic analysis in order to detect the inception of stall and validate the effectiveness of this process for identifying the precursor of unstable compressor behavior.

An in-depth literature review of the past 75 years of research on stall and surge was recently written by Day [22]. In [22] he gave evidence of another important approach, also adopted by Gallus and Hoenen [23], in order to detect stall inception disturbances. The authors analyzed the blade passing signal noticing that, as the compressor draws near to the stall limit, this signal repeatability declined. A similar study with similar results was then carried out by Inoue et al. [24] who confirmed this phenomenon. Further, a correlation, developed by Dhingra et al. [25], between degradation of blade passing signature and closeness to stall, was successfully adjusted and applied by Christensen et al. [26] to a real engine control system.

Because of the importance and the consequences that stall causes to turbomachines, this topic is still attractive to many authors. Dodds and Vahdati [27] performed an investigation of an 8 stage high speed compressor along a fixed working line. They induced stable rotating stall by mismatching the front stages through the variable stator vanes in order to establish the length-scale and propagation speed of stall disturbance by analyzing the data spectral content. They found that stall can occur at different frequencies and with diverse length scales depending on the stage in which it is generated.

During recent decades many authors have investigated various procedures for establishing the limit flow range of compressors before surge onset. Galindo et al. [28] used the air injection technique to measure the surge line of a turbocharger compressor, proving the advantages of this method in order to evaluate the influence of the inlet geometry and engine intake line acoustics.

Other works also focused on the surge phenomenon characteristics. In [29] a study on the frequency and amplitude of surge phenomena in different turbocharger compressors was performed confirming, as stated in [30], that the surge frequency was in the range $5-15 \mathrm{~Hz}$ and varied with the compressor velocity and downstream volume. Liu and Theng [31] proposed a reliable technique for finding surge points by using the standard deviation (SD) of the measurement data. The authors stated that the SD of fast-response thermocouple 
measurements is an effective surge diagnosis quantitative index.

Other recent specific experimental works on surge and surge limit analysis were developed in [32-35]. Kabalik et al. [32] investigated the influence, in a centrifugal blower, of the inlet duct configuration and its interaction with amplitudes and frequency of surge pulsations. They did not find a significant qualitative influence of the inlet duct volume on the spectra of pressure fluctuation at deep surge. The only parameter which was significantly subject to change was the amplitudes of the highest peaks. In [33] a study of surge precursor instabilities was carried out identifying rotating instabilities. The authors found that, when throttling the compressor toward surge, the rotating instabilities detected grew in amplitude and finally created a full-span stalled cell which induced surge to occur. The experimental campaign reported by Marelli et al. [34] aimed to study the characteristic performance map of a turbocharger compressor, even in the unstable operating region. They firstly defined an experimental method based on the surge occurrence pulsation at the compressor outlet in order to identify the surge line. Successively, they explored the left side of the surge line without causing surge thanks to the particular setting of their apparatus. In [35] instead, the unstable behavior of a high speed centrifugal compressor was analyzed and a description of a two-regime surge was presented by examining the different inception mechanisms of deep surge at different rotational speeds.

To conclude this section, it is worth highlighting that some modern works are trying to give a complete definition of the physical nature of stall and surge, and what exactly triggers it, from a different point of view. The work of Huang and Yin [36] can be classified in this context. They tried to demonstrate the independence of surge, at its initial stage, from the compression system characteristics. Using the experimental results obtained by Mazzawy [37], Freeman and Day [21] and following the path marked by the paper of Cargill [38], they hypothesize that an analogy exists between the transient dynamics of stall and surge and the shock tube theory.

This reveals the interest on this fundamental issue and confirms that research is continuing in order to provide an answer to the most significant remaining doubts.

\section{TEST FACILITY}

The experimental facility is located at the laboratory of the Engineering Department of the University of Ferrara. Figure 1 shows a simplified 3D sketch of the entire test rig (only the piping system) where the different colors highlight the main parts of the circuit. A more detailed description is given in the compression piping system paragraph. The compressor tested was manufactured by Allison and is part of the turbo-shaft engine 250-C18. This compressor has already been investigated in $[9,15,16]$. It is characterized by a suction diameter of 0.104 $\mathrm{m}$ where an IGV row is present. Then, six axial stages and one centrifugal stage precede a vaneless diffuser and two semivolutes, that conduct the flow out of the compressor through two circular exit sections with a diameter of $0.056 \mathrm{~m}$ each. At its nominal flight condition, the compressor achieves a pressure ratio of 6.2 , with a rotational speed of 51,600 rpm and a mass flow rate of $1.36 \mathrm{~kg} / \mathrm{s}$. The compressor is installed on the test bench with a new aluminum frame, specifically designed for this purpose, which is adaptable to various displacement adjustments. The description of the test rig is presented here in four main sub-paragraphs.

\section{Gear train system}

An asynchronous electric brake/motor, typically devoted for automotive engine testing, with a maximum power $P_{\operatorname{mot} \text { max }}$ of $87 \mathrm{~kW}$ and a maximum rotational speed $N_{\text {mot,max }}$ of 5,000 rpm, was used here as a drive motor and remotely controlled by an inverter (i.e. variable frequency drive). The power transmission from the AC motor to the compressor block (gear boxes and compressor) was made through a constant-velocity joint which reduced and tolerated vibrations due to misalignment between the shafts of the electric motor and the main gear train. The Allison engine original gear box was kept connected to the compressor but with the auxiliary utilities removed. Moreover, in order to achieve higher rotational speeds, the planetary reduction gear connected to the original engine power shaft (to transmit power to the propellers), was adapted to be installed in the test rig as a multiplier. The resulting total gear ratio was thus equal to 17.26:1. The entire mechanism was lubricated by an ad hoc oil circuit, composed of a heat exchanger fed with cool water.

\section{Compression piping system}

As shown in Fig. 1 the compressor inlet was preceded by an inlet duct with a length of about $3 \mathrm{~m}$. This length was established as a compromise between the available space and the space required upstream and downstream of the installed orifice plate and mass flow rate sensor.

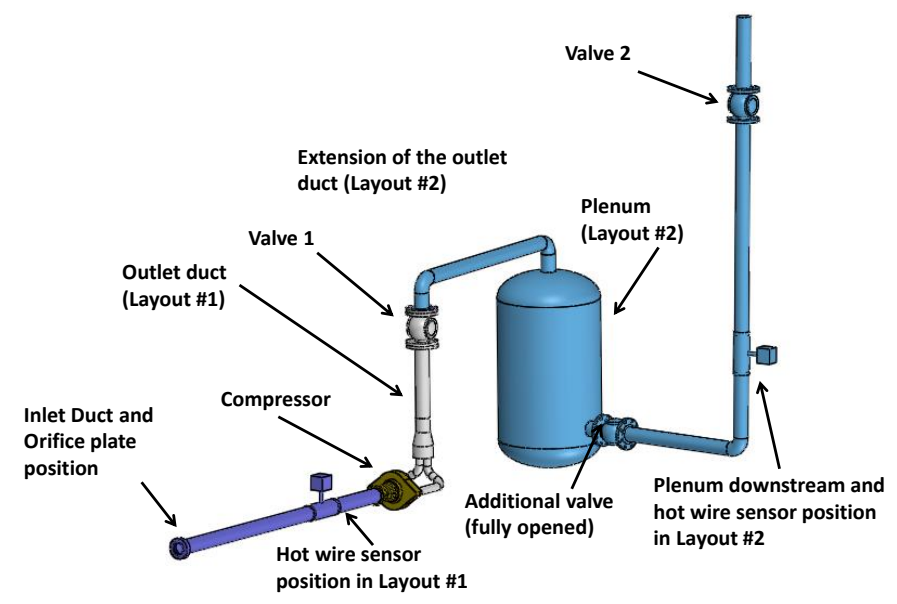

Fig 1. 3D sketch (colored) of the piping system: in violet the inlet duct, light brown the compressor, grey the outlet duct of Layout \#1, in blue the added part belonging to Layout \#2 . 
A new flow conveyor was then installed just downstream of the compressor. Its function is to guide the two centrifugal compressor outflows into a single duct. It was designed through CFD simulations, in order to find an optimal compromise between space limitations, the need to minimize pressure losses, and cost.

The piping system was intended to be modular in order to allow two different configurations at the compressor outlet.

In the first configuration, Layout \#1 in Fig. 2a, after leaving the compressor, the flow path consisted of the conveyor, a short duct (the minimum length required to achieve a uniform sectional flow) and a solenoid throttling valve. In Layout \#1, the orifice plate and the hot wire sensor were both placed along the inlet duct to measure the mass flow and, at the same time, to determine a sort of alignment or correlation between the two measurements.

On the other hand, in the second arrangement, Layout \#2 in Fig. $2 b$, the flow path was modified by adding a plenum and, after another duct, a second solenoid downstream. In Layout \#2 the hot wire sensor was placed downstream of the plenum.

Layout \#2 was used to lead the compressor to surge so, according to Greitzer [6], the value of the non-dimensional parameter $\mathrm{B}$ had to be greater than 0.8 during the dynamic tests. Based on Tab. 1, which reports the values of B at each rotational speed tested in dynamic tests, surge was expected to occur already at 5,000 rpm.

Table 2 shows the dimensions of the different pipes belonging to the entire system so that the size of the whole facility is more clear.

Table 1. Values of non-dimensional parameter $B$ referred to Layout \#2.

\begin{tabular}{c|c} 
Rotational speed & $\boldsymbol{B}$ \\
\hline $5,000 \mathrm{rpm}$ & 1.04 \\
$10,000 \mathrm{rpm}$ & 2.08 \\
$15,000 \mathrm{rpm}$ & 3.12 \\
\hline
\end{tabular}

Table 2. Pipe line dimensions and volumes.

\begin{tabular}{l|c|c|c}
\multicolumn{1}{c|}{ Duct } & $\begin{array}{c}\text { Equivalent } \\
\text { pipe length } \\
{[\mathbf{m}]}\end{array}$ & $\begin{array}{c}\text { Equivalent } \\
\text { pipe diameter } \\
{[\mathbf{m}]}\end{array}$ & $\begin{array}{c}\text { Volume } \\
{\left[\mathbf{m}^{3}\right]}\end{array}$ \\
\hline Inlet-first segment & 1.500 & 0.109 & 0.014 \\
\hline Inlet-second segment & 1.390 & 0.099 & 0.011 \\
\hline $\begin{array}{l}\text { Centrifugal } \\
\text { compressor outlets }\end{array}$ & 0.900 & 0.050 & 0.002 \\
\hline Conveyor & 0.130 & 0.11 & 0.001 \\
\hline $\begin{array}{l}\text { From conveyor to } \\
\text { Valve \#1 }\end{array}$ & 0.480 & 0.099 & 0.004 \\
\hline $\begin{array}{l}\text { From Valve \#1 to } \\
\text { plenum }\end{array}$ & 3.220 & 0.099 & 0.025 \\
\hline Plenum & -- & -- & 1.5 \\
\hline $\begin{array}{l}\text { From Plenum to } \\
\text { Valve \#2 }\end{array}$ & 5.420 & 0.099 & 0.042 \\
\hline
\end{tabular}

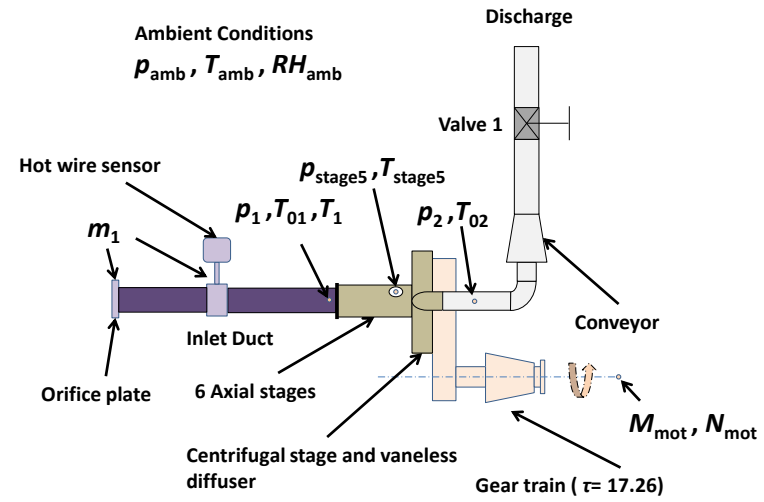

a

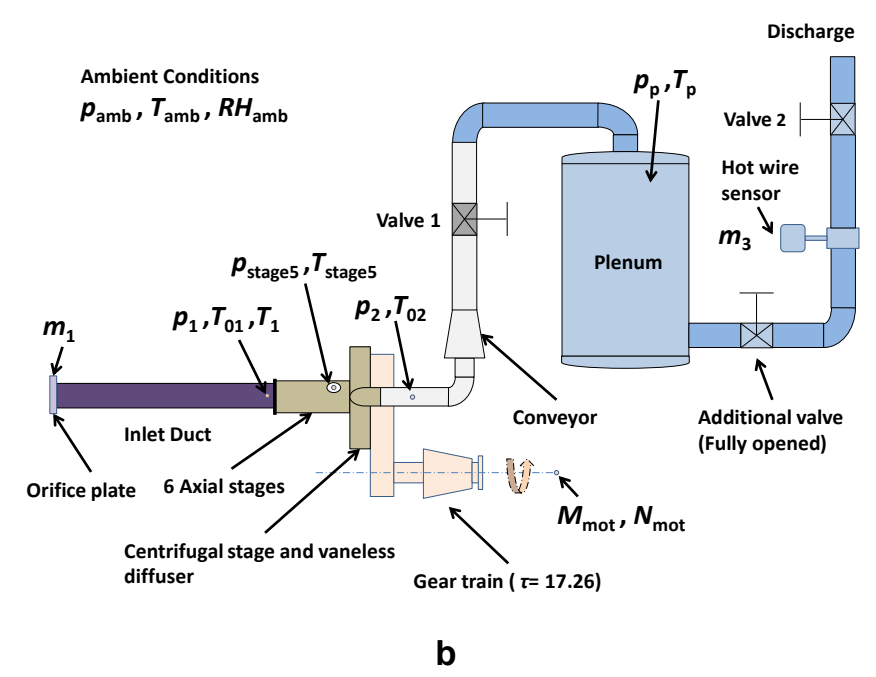

Fig 2. 2D sketch of the piping system: a) Layout \#1 b) Layout \#2.

\section{Measurement Sensor System}

Figure 2 shows in detail the type of measurement and the location of the sensors along the circuit. As stated in the previous paragraph, the mass flow rate was measured by an orifice plate at the compressor inlet and by a hot wire mass flow sensor placed at the inlet duct (Layout \#1) or at the plenum outlet duct (Layout \#2).

The electric motor rotational speed was obtained by a magnetic pick-up sensor fixed in the proximity of the motor wheel equipped with 60 teeth, while the torque is measured through a torquemeter $(0-250 \mathrm{Nm})$ at low regimes and through a load cell (not used in this work) at high regimes.

Pressure transducers were located along the circuit to measure the absolute static pressure through annular chambers or rings, whereas thermocouples measured the stagnation temperatures at the compressor inlet, and outlet. All measurements are considered to be averaged annulus quantities. 
The calculation of stagnation pressure and static temperature was performed considering the operating fluid as a perfect mixture of dry air and water vapor, through the same procedure explained in [9]. Static temperature and static pressure values were also acquired at the bleed valve position and inside the plenum. All the sensors on the test rig were used to evaluate i) the compressor steady-state characteristic curves, and ii) the dynamic response of the compressor during surge (the expected phenomenon frequency range was $0-15 \mathrm{~Hz}$ ). Finally, two Kulite fast respond miniature piezoresistive transducers (XQ-093 series) were located circumferentially (spaced $180^{\circ}$ from each other) at the compressor inlet in order to detect local instabilities (stall onset and development of rotating stall cells).

Table 3 shows the main characteristics of the instrumentation installed on the test rig. All the sensors were adequately calibrated before proceeding with the performance tests.

\section{Control and Acquisition System}

The electric motor was operated by an inverter which was linked to a control unit. This unit is required by the operator to set the electric motor driving mode (constant rotational speed or constant torque) and the inverter controlling mode: manual (through the installed potentiometer) or automatic (through external hardware).

The tests were carried out by setting the constant rotational speed mode and through remotely controlling the inverter by using a specific cDAQ signal output module, also used for controlling solenoids, and another solid state relay module needed to remotely activate the inverter.

The ambient conditions were recorded by a specific environmental monitoring station. Due to the short duration of each test, the ambient conditions were constant throughout the experiments.

In Fig. 3 a schematic diagram of the data control and acquisition system is illustrated.

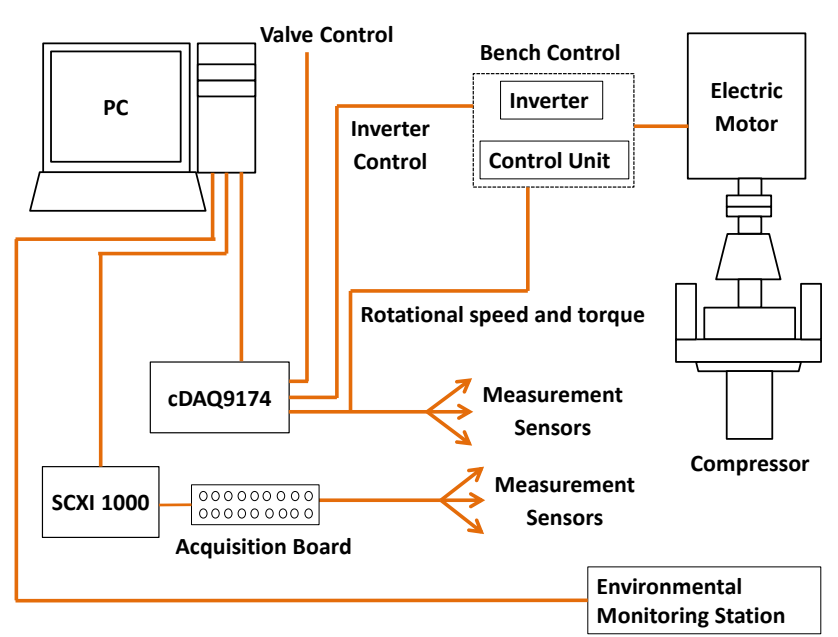

Figure 3. Diagram of the control and acquisition system.
According to the maximum frequency response of the sensors and the characteristics of the acquisition modules, a distinction between the low frequency part and the high frequency part was made.

The low frequency analog signals were acquired by an NI compact DAQ-9174 chassis, and then converted into digital through two different modules installed: a 16-channel module (module 1, non-simultaneous maximum frequency of $70 \mathrm{~Hz}$ ) was dedicated to thermocouples and another 16-channel module (module 2, 8 voltage/8 current channels, nonsimultaneous maximum frequency of $500 \mathrm{~Hz}$ ) was used for pressure and mass flow sensor analog inputs. The high frequency measurements were performed by the NI SCXI-1000 chassis, with only one module installed and a 32-channel amplifier module (simultaneous maximum sample rate of 333 $\mathrm{kHz}$ ) devoted to the orifice plate differential pressure transducer, the electric actuator positioner transmitter and the electric motor rotational speed and torque.

These hardware components were integrated into the data acquisition system by a software program developed in Labview. This program was created with a conceptual design which allows the processes load on the CPU of the PC desktop dedicated to this test-rig to be minimized. This was done to avoid computer crashes during the tests, thus increasing the operational safety of the system.

The program allows a variable sampling frequency (see details in the Methodology paragraph), depending on the type of tests, and two different modes of data logging: dynamic and instantaneous.

Table 3. Instrumentation Characteristics.

\begin{tabular}{|c|c|c|c|}
\hline Instrument & Type & Range/Capacity & Characteristics \\
\hline $\begin{array}{l}\text { Valve } 1 \text { and } \\
\text { Valve } 2\end{array}$ & Ball & DN 100-PN 16 & $\begin{array}{l}\text { Cast Iron, } \\
\text { PTFE seals }\end{array}$ \\
\hline Actuator & Electric & $300 \mathrm{Nm}$ & $\begin{array}{l}\text { Positioner 0-10 V, } \\
\text { Position } \\
\text { Transmitter 0-10 V }\end{array}$ \\
\hline Orifice plate & $\begin{array}{l}\text { Extremity } \\
\text { throttling } \\
\text { device }\end{array}$ & ---- & $\begin{array}{c}\text { Diameters } \\
\text { ratio=0.7 }\end{array}$ \\
\hline $\begin{array}{l}\text { Mass flow rate } \\
\text { sensor }\end{array}$ & Hot wire & $0.95 \mathrm{~kg} / \mathrm{s}$ & 4" flow body \\
\hline $\begin{array}{l}\text { Pressure } \\
\text { transducers }\end{array}$ & Membrane & $0-3.5$ bar a & $\begin{array}{l}\text { Infinitesimal } \\
\text { resolvution, } \\
\text { amplified output }\end{array}$ \\
\hline Thermocouples & $\mathrm{J}$ and $\mathrm{K}$ & Typical & Sheathed \\
\hline $\begin{array}{c}\text { Fast response } \\
\text { pressure } \\
\text { transducers }\end{array}$ & Piezoresistive & $0-3.5$ bar a & $\begin{array}{l}\text { Infinitesimal } \\
\text { resolution. } \\
\text { Distance from } \\
\text { compressor inlet } \\
\text { equal to } 0.005 \mathrm{~m}\end{array}$ \\
\hline Torquemeter & $\begin{array}{l}\text { Double- } \\
\text { flange, } \\
\text { dynamic }\end{array}$ & $0-250 \mathrm{Nm}$ & $\begin{array}{l}\text { Resolution of } 0.1 \\
\text { Nm }\end{array}$ \\
\hline Pick-up & Magnetic & 0-9999 rpm & $\begin{array}{l}\text { Resolution of } 1 \\
\text { rpm }\end{array}$ \\
\hline
\end{tabular}




\section{METHODOLOGY}

As already explained in the previous paragraph, the test bench was driven by the constant speed mode control in order to the set the desired rotational speed at any time during the test. Therefore, once the rotational speed was set, the system ensures an optimum control of the AC motor rotational speed. The maximum rotational speed percentage variation recorded under test conditions at the compressor corrected rotational speed of 10,000 rpm, even during transient, was around $0.4 \%$. Only during surge peak values of $0.8 \%$ were recorded.

\section{Compressor Steady State Performance maps}

The compressor characteristic maps were obtained by testing the machine with the plant Layout \#1 presented in Fig. $2 \mathrm{a}$ in order to minimize the circuit pressure losses and extend the mass flow operating range. Moreover, this configuration allowed the achievement of reliable results even at the left of the characteristic curve peak because the compressor could not surge due to the absence of mass storage and flow inertia (considering the inlet duct flow inertia to be negligible). Therefore, even operating points on the positive slope of the characteristic curve were identified because the compressor reached stable working conditions and did not show average mass flow or pressure oscillations. This situation was maintained until the point of static instability which caused rotating stall as explained in [2].

The tests aimed to describe the stable behavior and characteristic maps of the compressor at different shaft corrected rotational speeds $v$ : 5,000, 10,000, 15,000, 20,000, $25,000 \mathrm{rpm}$. Each curve was obtained by throttling via software the solenoid valve (Valve 1) from $\alpha=90^{\circ}$ (valve completely opened) to a specific closing angle, established by the authors' experience and knowledge of the test-rig before any unsafe situation could arise on the compressor system and sensors (change of sound and vibrations was an appropriate precursor for dangerous conditions). The closing of Valve 1 occurred with steps of $5^{\circ}$. For each step the measurement signals were acquired after setting the compressor corrected rotational speed (by software) and waiting long enough for the measurement values to stabilize. This methodology, coupled with the reliable control and data acquisition system, was useful in obtaining experimental data at conditions closely corresponding to the desired compressor rotational speed, $v$, despite the slight inevitable electrical/mechanical instability of the motor speed ( $N_{\text {mot }}$ variation was 1-5 rpm) at a very low regime (below 5,000 rpm).

The performance parameters used to determine the compressor operating points were the total-to-total pressure ratio $\beta_{0}$ and the isentropic efficiency $\eta_{\text {is }}$ as function of the nondimensional corrected speed $v$ and of the non-dimensional corrected mass flow rate $\mu$.

\section{Compressor Dynamic Test and Surge Inception}

This series of tests was executed by running the compressor at 10,000 and 15,000 rpm with Layout \#2 (as described in the Test Facility paragraph and shown in Fig. 2b) in order to create the necessary conditions for surge onset and development. The first step of this experiment was to linearly accelerate the compressor up to the corrected rotational speed of $10,000 \mathrm{rpm}$. The valve located immediately after the compressor (Valve 1) was kept fully open. The experiment was then carried out by closing at a specified angle the valve located downstream of the plenum (Valve 2). The closing/opening velocity of the valve was $1.5 \%$. In the vicinity of the characteristic curve peak, when the valve was closed further, dynamic instability was achieved and compressor surge occurred (see [2]). Valve 2 was then stopped for a time range suitable to permit the complete development of surge. After that, Valve 2 was progressively reopened to restore stable conditions and evaluate the hysteresis which characterized stall and surge phenomena in this system. The dynamic data were acquired throughout this process and evaluated by plotting the oscillating values of mass flow sensors pressure transducers and thermocouples measured at the compressor inlet and outlet as functions of time.

Other significant parameters analyzed for detecting surge conditions were the plenum pressure, $p_{\mathrm{p}}$, mass flow rate, $m_{1}$ and $m_{3}$, and normalized power, $P_{\text {el,norm }}$, (through the measurement of the torque, $M_{\text {mot }}$, at the motor shaft) required by the electric motor,

$$
P_{\text {el,norm }}=\frac{P_{\text {el,mot }}}{P_{\text {mot,max }}}
$$

where

$$
P_{\text {el,mot }}=\frac{2 \pi N_{\text {mot }} M_{\text {mot }}}{60}
$$

For both types of tests presented in this paper, the Labview program recorded data at a frequency of $10 \mathrm{~Hz}$ but cDAQ and SCXI were set to a sampling frequency of $10 \mathrm{kHz}$. Obviously, only the data acquired by the SCXI had effectively that desired frequency thanks to its great velocity feature; on the other hand cDAQ modules had a sampling frequency equal to

$$
f_{\text {cDAQ,mod } 1}=\frac{500}{c_{\bmod 1}}=\frac{500}{10}=50 \mathrm{~Hz}
$$

where $c_{\bmod 1}$ is the number of channels activated in module 1 , and

$$
f_{\mathrm{cDAQ}, \bmod 2}=\frac{70}{c_{\bmod 2}}=\frac{70}{10}=7 \mathrm{~Hz}
$$

where $c_{\bmod 2}$ is the number of channels activated in module 2 .

The results and discussion of this experimental investigation are presented in the next paragraph.

\section{TEST RESULTS AND DISCUSSION}

Before presenting the test series results it is important to highlight, once more, that all the sensors, pressure transducers, and thermocouples, were calibrated using a proper calibrator provided with a valid certificate of calibration issued by an authorized institution. Another important factor to point out is that the signal noise was significantly reduced thanks to the use of shielded cables and positioning the acquisition systems outside the shielded box so that the electro-magnetic 
disturbances coming from the inverter and the motor were minimized, although still present. The typical network electric noise was then further reduced by supplying the power to the sensor by means of $12 \mathrm{~V}$ batteries. Based on these considerations, it should be underlined that the measurement errors are rather insignificant compared to the variation in the actual physical magnitudes themselves. Therefore, the results and the consideration reported in the next paragraphs can be considered reliable and repeatable as much for steady state as for dynamic tests. Table 4 illustrates the ambient conditions of each test conducted at specific corrected rotational speeds.

\section{Steady-state behavior}

The characterization of the steady state points was carried out using the circuit in Layout \#1. Figures 4, 5 and 6 illustrate the compressor characteristics at the different rotational speeds. It is clear that the piping system configuration also allowed a description of the positive slope part of these curves to be identified. Each point was obtained through 3-5 different measurements executed arbitrarily in a maximum time of $3 \mathrm{~s}$. For each of these three measurements, 1,000 data values were acquired in a time of $0.1 \mathrm{~s}$ and an average of each parameter was calculated.

It is important to note that, at low rotational speeds $(5,000$, 10,000 and 15,000 rpm), data acquisition was done for all the valve opening positions whereas at high velocity $(20,000$ and $25,000 \mathrm{rpm}$ ) the maximum achieved closure was $10^{\circ}$ and $25^{\circ}$ respectively, due to burble sounds and increasing vibration which could cause some damage to the instrumentation.

At 5,000 rpm most of the overall pressure rise (see Fig. 4) seemed to be given by the centrifugal stage (the trend was similar to that of the theory of centrifugal compressors) while the axial compressor did not contribute significantly. This appeared evident by observing the static pressure ratio at stage five (where the bleed valve was originally placed) shown in Fig. 6.

Table 4. Ambient Conditions during tests.

\begin{tabular}{c|c|c|c|c}
$\begin{array}{c}\text { Corrected } \\
\text { Rotational } \\
\text { Speed }\end{array}$ & Type of test & $\boldsymbol{p}_{\text {amb }}[\mathbf{m b a r}]$ & $\boldsymbol{R} \boldsymbol{H}_{\text {amb }} \%$ & $\boldsymbol{T}_{\text {amb }}\left[{ }^{\circ} \mathbf{C}\right]$ \\
\hline \multirow{2}{*}{$5,000 \mathrm{rpm}$} & Steady-state & 1021 & 43.2 & 22.6 \\
& Dynamic & 1026 & 37.5 & 20.8 \\
\hline \multirow{2}{*}{$10,000 \mathrm{rpm}$} & Steady-state & 1020 & 44.5 & 22.7 \\
& Dynamic & 1026 & 32.8 & 20.9 \\
\hline \multirow{2}{*}{$15,000 \mathrm{rpm}$} & Steady-state & 1020 & 44.7 & 22.7 \\
& Dynamic & 1026 & 37.5 & 20.8 \\
\hline \multirow{2}{*}{$20,000 \mathrm{rpm}$} & Steady-state & 1020 & 44.7 & 22.7 \\
& Dynamic & - & - & - \\
\hline \multirow{2}{*}{$25,000 \mathrm{rpm}$} & Steady-state & 1019 & 46.2 & 21.9 \\
& Dynamic & - & - & - \\
\hline
\end{tabular}

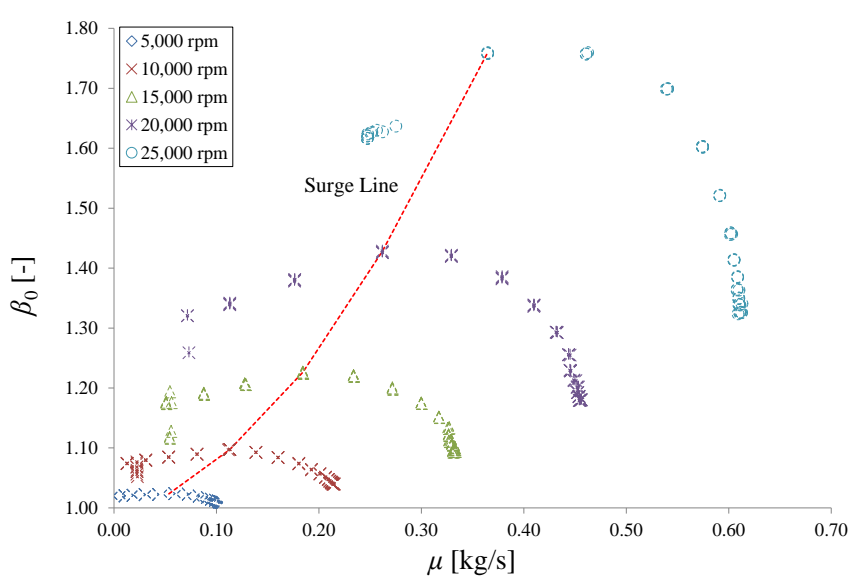

Figure 4. Steady state performance map: Pressure ratio.

It is clear that at low rotational speeds the axial stages worked off-design, destabilizing the overall performance. This was probably due to the stall regions of the first stages, and the choking phenomenon of the latter stages which both affect their performances (the bleed valve was not present whereas under these operating conditions it should be opened to prevent this behavior). As the velocity was increased, this phenomenon progressively diminished, as expected by theory, and the negative slope increased. In Fig. 4, at 20,000 rpm and 25,000 rpm, the overall characteristic presented a choking area at high mass flow rate. This testified that the increasing performance of the axial stages contributed more to the overall compressor characteristics. Due to the lack of manufacturer data, the surge line shown in Fig. 4 was simply estimated by using the peak values of the characteristic curves at each performed rotational speed.

Figure 6 shows a wide scatter between values belonging to low mass flow rates. In this region, instability was prevalent so the operating point experienced a continuous and alternated repositioning between the characteristic curve and the stalled curve. Moreover, as already mentioned, the bleed valve was removed and the bleed chamber was plugged to install the temperature and pressure sensors. Due to the characteristic shape of the bleed valve section, the air at the fifth stage, accumulated in a circumferential volute which directly connects the air to the bleed valve chamber. This volute circumferentially increases its internal volume towards the bleed valve chamber. The accumulation of mass flow inside this volute produced a sort of hysteresis effect, which sometimes amplified the compression ratio slightly over the peak of the curve. Therefore, the operating point did not immediately change position between the characteristic curve and the stalled curve, but went through a path that is difficult to reconstruct through instantaneous measurements. The combination of these conditions led to the scattered trend reported in Fig. 6 for very low mass flow. The scatter, and thus the path, increased with the rotational speed because the perturbation had higher amplitudes. 
In the curve at 20,000 and higher, this phenomenon was not present because Valve 1 was not completely closed.

After the occurrence of stall, it is evident that the compressor no longer reached a stable condition, generating a continuous shift between the characteristic and stalled curve. A longer waiting time for stabilization would generally allow this phenomenon to be reduced but so as not to compromise the integrity of the system, the test methodology (closing of the valve and data logging) was applied with a reduced waiting time for the stabilization of the parameters. In fact, the aim of this analysis was only to determine the characteristic curve and identify the point where instability occurred.

Figure 5 illustrates the isentropic efficiency curves, corresponding to the same data of Figs. 4 and 6 . The static instability was evident, by the deviation (scattering) between the last two-three points of the curve (especially at 10,000, 15,000 and $20,000 \mathrm{rpm}$ ) on its positive slope part. This behavior was consistent with stall because overall mass flow was almost constant and the operating point suddenly dropped (see Figs. 4 and 6), which means that stall was achieved through a sudden pressure ratio drop.

The static instability was only found for curves at 5,000, $10,000,15,000$ and 20,000 rpm while it was not found at $25,000 \mathrm{rpm}$ because Valve 1 was not completely closed in this test.

An important note to mention is that the mass flow rate values, $m_{1}$, utilized for determining the curves of Fig. 4, 5 and 6 were those of the hot wire sensor, since the measurements were more reliable than those of the orifice plate at low flow regimes. The mass flow rate data did not achieve a zero value even when the valve was totally closed, which is only due to the type of mass flow rate sensor (hot wire type) which has difficultly showing zero mass flow due to its proximity to the compressor inlet (which implies the presence of vortices and stalled cell perturbations) and the lack of stabilization of the operating point in the stalled curve.

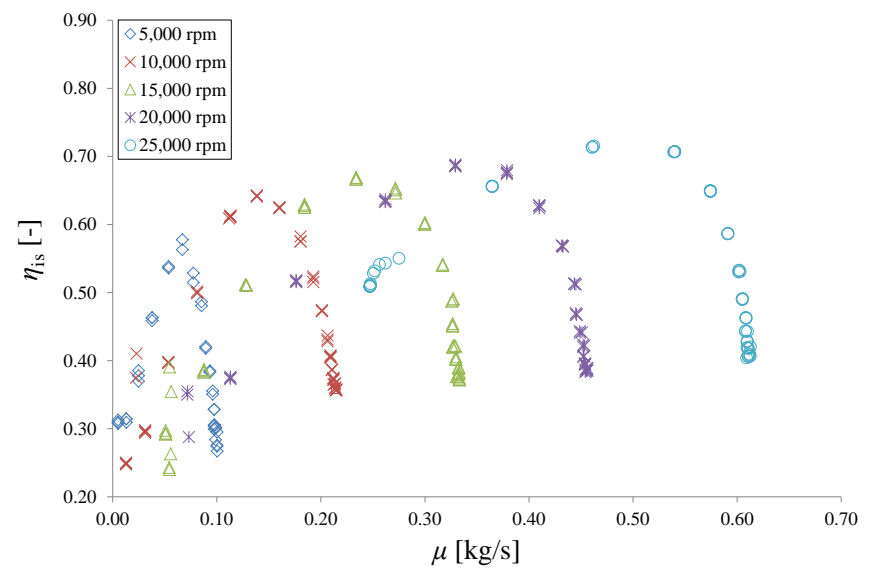

Figure 5. Steady state performance maps: Isentropic efficiency.

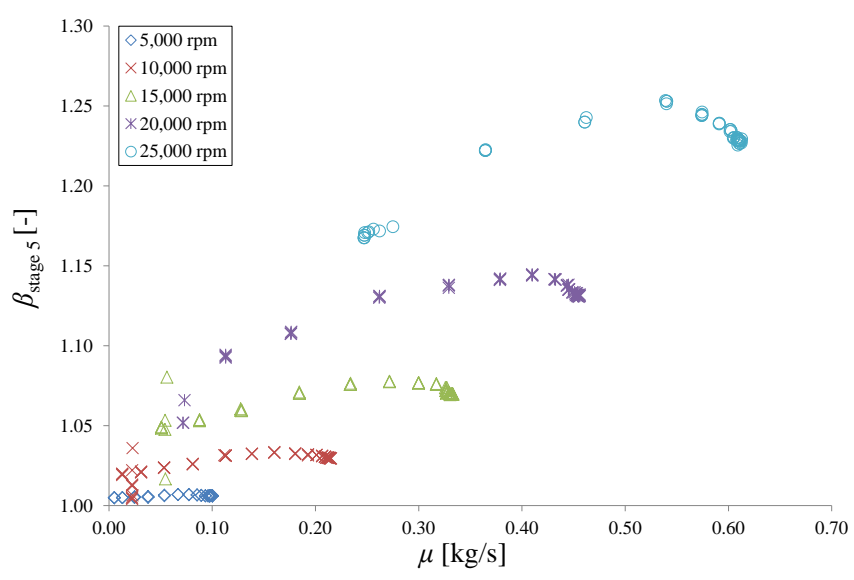

Figure 6. Steady state performance maps: Static pressure ratio at stage five (bleed valve position).

\section{Dynamic behavior}

The dynamic tests were carried out configuring the piping system in Layout \#2. These tests were performed following some specific steps. After an initial linear increase, until the desired rotational speed $v$, stabilization of the parameters was achieved and a stall ramp (i.e. the characteristic curve toward stall and/or surge) was initiated by closing Valve 2 at constant velocity (see Compressor Dynamic Tests and surge inception paragraph). When surge occurred, the valve was stopped for a sufficient amount of time for the development of instability to be completed and then it was opened again. Figure 7 shows the trend of the most important measurements monitored during the test at $v=10,000 \mathrm{rpm}$. It is evident, by looking at the mass flow recorded downstream of the plenum (by using the hot wire sensor) and upstream of the compressor (using the orifice plate), that surge started when $\alpha=25^{\circ}$. A particular note needs to be made regarding these two measurements: during surge, the value downstream of the plenum was subjected to low amplitude oscillations because the flow was more stable. In fact, the $\Delta p_{\text {p-amb }}$ was always positive during the test and the plenum attenuated the fluctuation amplitude downstream thereof.

By looking at Fig. 7 an important point to highlight is that the surge cycle was shown to be well captured, not only by the static pressure transducers but also by the electric motor absorbed electric power (calculated through the torque meter data referred to $M_{\text {mot }}$ ), and by the thermocouple which measures the compressor inlet stagnation temperature. Also $T_{02}$ and $T_{\text {stages }}$ (not illustrated) showed a significant and progressive increment during surge, but the characteristic oscillations of surge were less evident. This means that classic thermocouples are sufficient to detect surge when positioned to measure stagnation temperature, especially at the inlet of the compressor.

Figure 8 confirms what is stated above by presenting the recorded values of the outlet pressure, $p_{2}$, alongside the two mass flow rates, $m_{1}$ and $m_{3}$, and the normalized absorbed electric power. The pressure fluctuations demonstrated 
excellent correspondence, not only with $m_{1}$ but also with $p_{\mathrm{p}}$ (not shown in the plot) and $P_{\text {el,norm}}$. Their oscillation amplitudes were compatible and their trend clearly followed the rapid change in the flow field. The frequency of the surge oscillation was around $0.7 \mathrm{~Hz}$ and the maximum compressor outlet pressure deviation between $p_{2 \max }$ and $p_{2 \min }$, with respect to the mean of $p_{2}$ during surge, was 0.04 bar. A very close result was found for $p_{\mathrm{p}}$ as well. It can be noted that $m_{3}$ showed limited oscillation amplitudes but of the same frequency as those which characterized $m_{1}$.

The characteristic curve and the path of the compressor operating point during the dynamic test is presented in Fig. 9. As can be seen, this plot was composed by the initial ramp (blue circles) in order to achieve the rotational speed of 10,000 $\mathrm{rpm}$, the stall ramp (blue diamonds), obtained by a linear closure of Valve 2, the surge cycle with the reversal flow (red crosses, at this point of the test Valve 2 was at $25^{\circ}$ but was still closing), and a final curve (green circles) obtained by opening the valve in order to recover from surge. Dynamic instability was achieved a few instants after the operating point approached the surge line (calculated by using the peaks of steady-state characteristic maps). Successively, instability could totally develop describing several times the surge cycle. Similar behavior occurred during the dynamic tests at $v=5,000$ and $v=$ $15,000 \mathrm{rpm}$. This is an important result because it ensures that steady-state surge line, as simply calculated here, is a reliable, and even preventive, surge-approaching indicator even during transients of the compressor. Figure 9 also shows that the compressor experienced rotating stall before deep surge, which occurred at each surge cycle. In fact, once the surge phenomenon started, the operating point demonstrated i) movement from the peak of the characteristic curve to the stalled curve, then ii) high oscillations at very low mass flow regimes, and finally, iii) movement along the stalled curve towards the characteristic curve before the cycle was repeated again. This behavior appeared to be the same even at $v=5,000$ and $v=15,000 \mathrm{rpm}$. During the opening of Valve 2, a hysteresis phenomenon was noted, which delayed the return of stable compressor conditions.

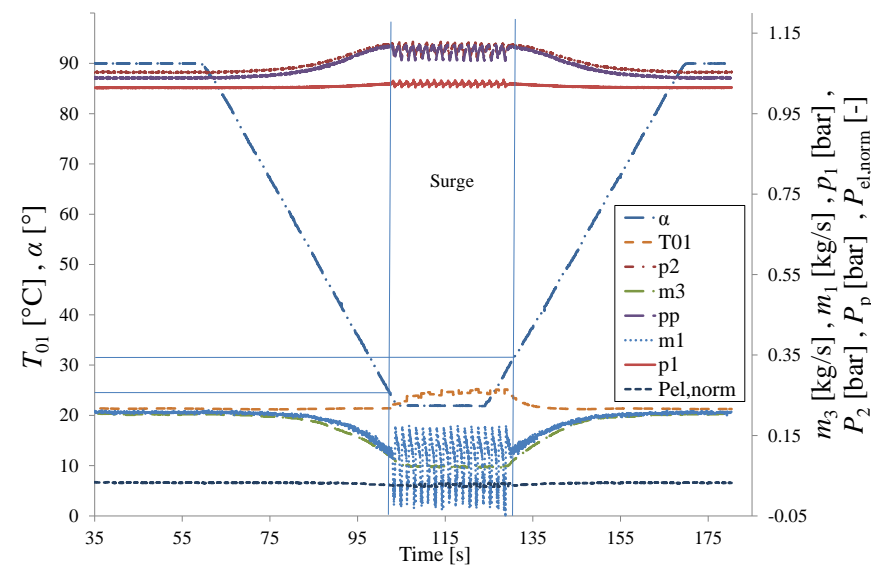

Figure 7. Dynamic Test @ v=10,000 rpm.

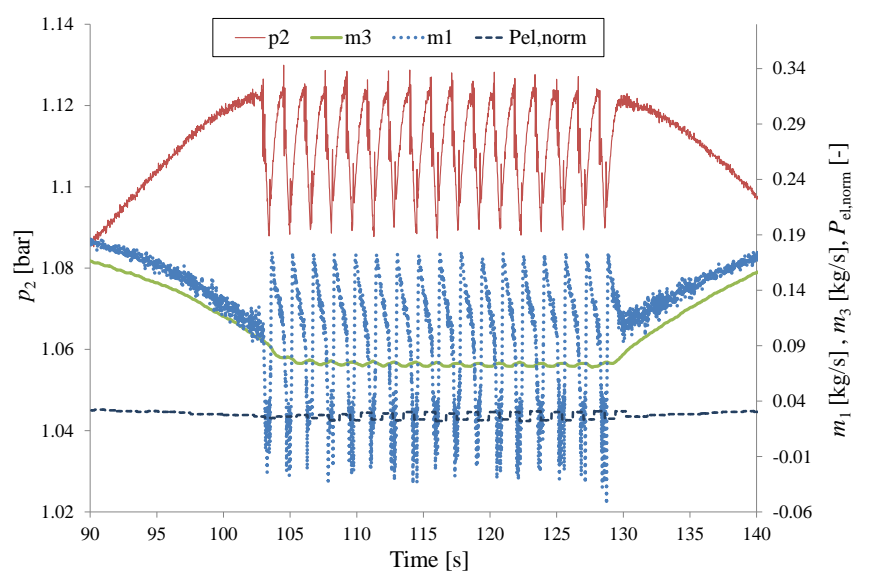

Figure 8. Dynamic test @ v=10,000 rpm. Typical Surge oscillation encountered on $p_{2}, m_{1}, m_{3}$ and $P_{\text {el,norm}}$.

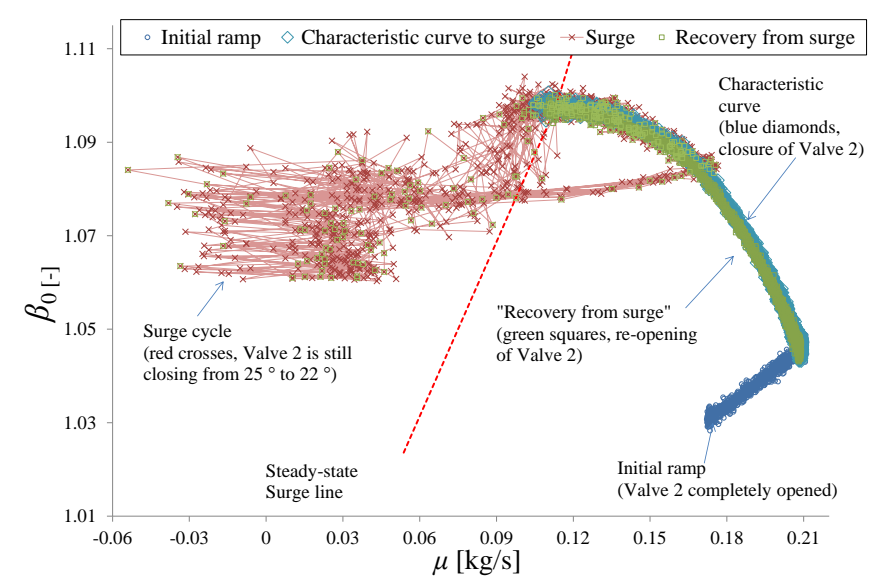

Figure 9. Dynamic Test @ v=10,000 rpm. Characteristic curve towards to surge and recover from surge.

This fact is observable in Fig. 7 where it is evident that surge started at a closing angle $\alpha=25^{\circ}$, whereas the recovery from instability occurred at about $\alpha=33^{\circ}$. Very similar results to those illustrated were obtained at $v=15,000 \mathrm{rpm}$ (in Fig. 10 the typical $p_{2}, m_{1}, m_{3}$ and $P_{\text {el,norm }}$ oscillations during surge are presented) and at $v=5,000 \mathrm{rpm}$. At $15,000 \mathrm{rpm}$, surge pulsations (see Fig. 10) occurred with a frequency of $0.5 \mathrm{~Hz}$ with approximately doubled amplitudes compared to $v=10,000$ $\mathrm{rpm}$. At 5,000 rpm the oscillation presented a frequency of $1 \mathrm{~Hz}$ with significantly reduced amplitudes compared to those at higher rotational speeds.

The dynamic tests were also used to study the mechanisms of surge inception in an attempt to detect the local perturbations which lead to this phenomenon. 


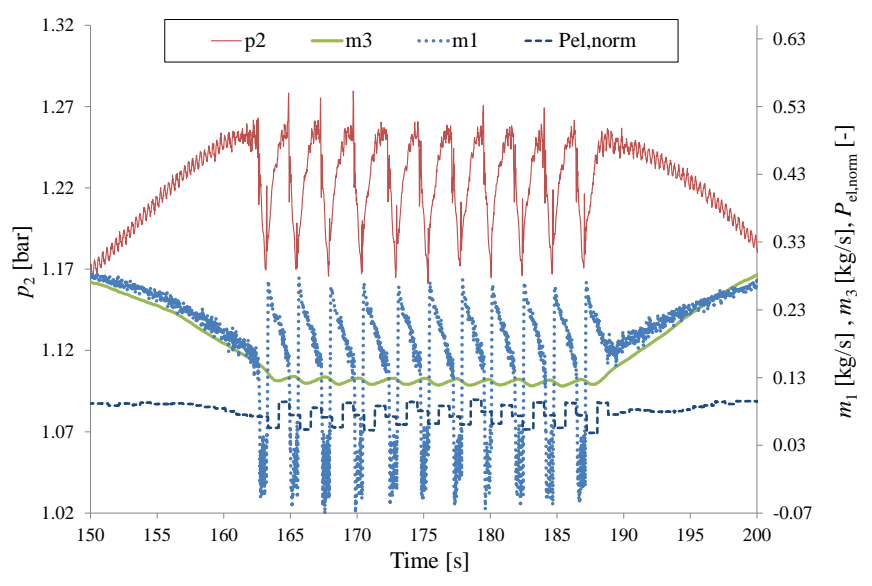

Figure 10. Dynamic Test @ $v=15,000 \mathrm{rpm}$. Surge pulsations of $p_{2}, m_{1}, m_{3}$ and $P_{\mathrm{el}, \mathrm{norm}}$.

This study was done by investigating the results obtained by the two fast response piezoresistive pressure transducers (Kulite XQ-093 series), located circumferentially (at a relative angular distance of $180^{\circ}$ to each other) immediately before the compressor inlet (see Tab. 2). The study was initially focused on the instants before surge in order to identify its inception phenomena. Figure 11 reports the trend of dynamic pressure value amplitudes at the compressor inlet. The scattered trend, which precedes surge, was clear evidence of rotating stall conditions. Moreover, from this figure it is evident that after surge inception, surge and stall are alternatively present; in other words, each surge cycle is originated by a short period of rotating stall. This behavior agrees with the typical behavior of axial machines [39] and with the operating point path of Fig. 9. A frequency domain analysis was then conducted on the signals of these two transducers and the result of Kulite \#1 is shown in Fig. 12 (similar results were obtained from Kulite \#2).

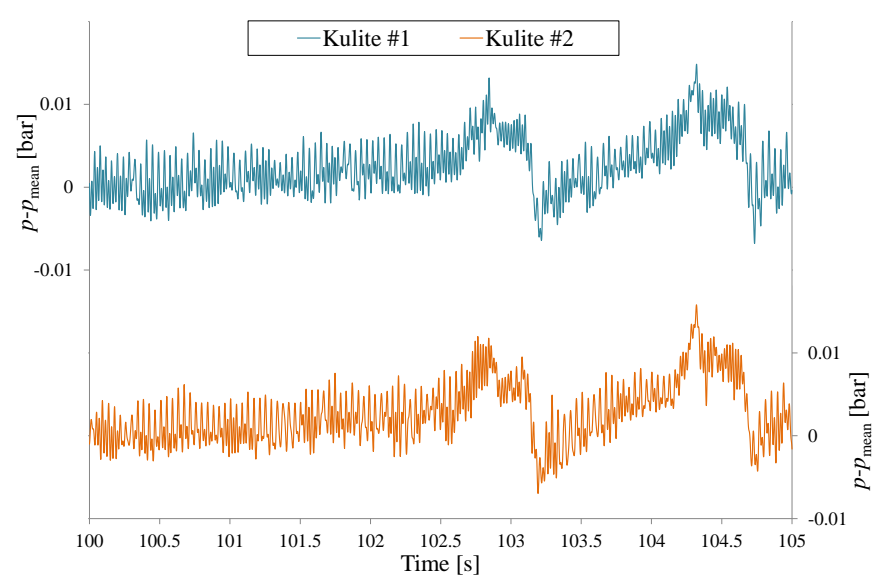

Figure 11. Dynamic Test @ v $v=10,000$ rpm. Fast response transducers signals at compressor a few instants before surge.

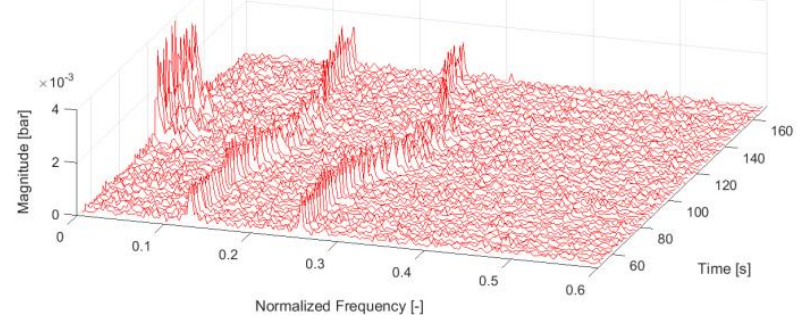

Figure 12. Dynamic Test @ v=10,000 rpm. Stall analysis at compressor inlet. Frequency domain analysis.

This figure represents the waterfall diagram (referred to the dynamic test at $10,000 \mathrm{rpm}$ ) of the fast Fourier transform, in terms of frequency normalized to the rotor revolution frequency, at time intervals of $2 \mathrm{~s}$ throughout the experiment.

It should be noted that a fluid dynamic perturbation (and the relative second harmonic) was present during the dynamic test. Its characteristic frequency, initially at $13 \%$ of the rotor speed, increased until $15 \%$ during the closure of Valve 2. During the surge cycle, the dominant frequency was that of surge pulsations, i.e. $0.7 \mathrm{~Hz}$ while the fluid dynamic perturbation seemed to be less marked and with a minor amplitude. When Valve 2 started to be re-opened and the compressor recovered from surge, the frequency of the perturbation recovered its original characteristics.

This phenomenon is compatible with a stall cell which is rotating at about $13 \%$ of the rotor speed. The stalled cell grew as the compressor was going towards surge; the increase in its frequency was valid evidence of this because, as the boundary interface was growing, the sensors were detecting this rotating cell more frequently.

It should be emphasized that, as the test was conducted at a rotational speed of $10,000 \mathrm{rpm}$ the compressor was far from its nominal operating conditions. This is evident by observing in Fig. 6 the destabilizing effect of the axial part of the compressor. Therefore, even with Valve 2 completely open, the presence of stalled cells was expected, as the frequency analysis confirmed.

Figure 13 shows the oscillations recorded by the two fast response transducers at $v=10,000 \mathrm{rpm}$ with Valve 2 completely open. In this figure, the rotating perturbations induced by the stalled cell are easily recognizable. The two signals are highly comparable to each other and their frequency is exactly the same (13\% of the rotor speed). Moreover, their phase shift, in temporal values, is around $0.024 \mathrm{~s}$ (consistent with their rotational speed). 


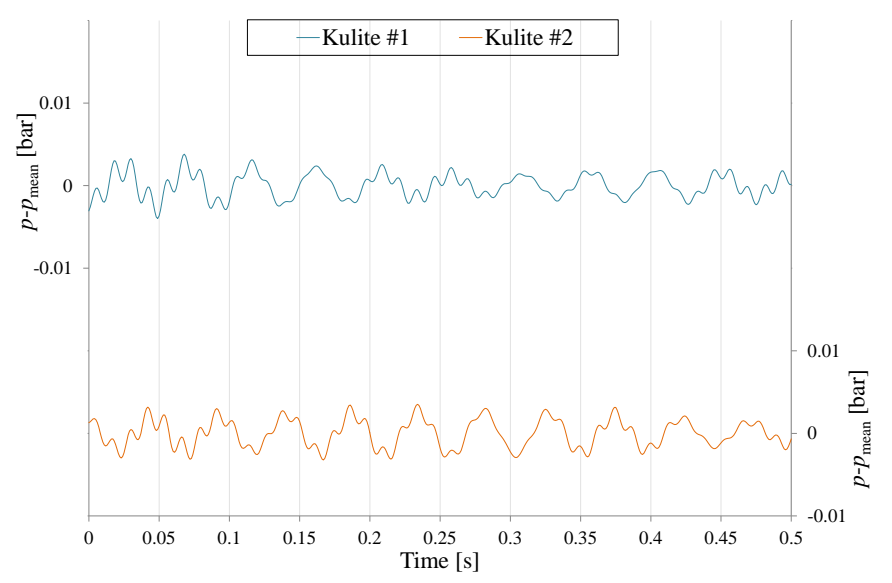

Figure 13. Dynamic Test @ v=10,000 rpm. Stall analysis at compressor inlet. Complete development of rotating perturbations.

\section{CONCLUSIONS}

This paper describes an experimental campaign to analyze the performance of an axial-centrifugal compressor. The aim was to investigate the steady state and the dynamic behavior of the compressor, through the determination of the characteristic maps, the analysis of surge instability and its inception mechanism.

A detailed description of the test rig, the acquisition system and the methodology used for the tests was reported. The test rig proved to be effective in the characterization of the stable and unstable behavior of an axial-centrifugal compressor. It could be configured in Layout \#1 and Layout \#2, the former used for the steady-state performance evaluation and the latter for the dynamic tests.

The first series of tests demonstrated that:

- As expected, the high speed compressor at low velocity did not receive an important contribution to the pressure rise from its axial stages which had a clear destabilizing effect, but as the velocity increased, the characteristic curve of these stages achieved a more stabilized and typical trend.

- Static instability was reached and identified by the abrupt drop in $\beta_{0}$ when stall occurred.

The dynamic tests performed showed that:

- $\quad$ The surge line, which was simply estimated by using the peak values of the steady-state characteristic maps, showed to be reliable for transient as well. It demonstrated to be a precautionary parameter for preventing the dynamic instability during the dynamic test at the performed rotational speeds.

- Deep surge occurred at very low mass flow values generating backflow. The operating point, at each surge cycle, moved from the characteristic curve to the stalled curve, then experienced high oscillations and moved along the stalled curve towards the characteristic curve.
- $\quad$ Deep surge pulsations were detected satisfactorily by all the static pressure sensors, and mass flow measurement at the compressor inlet and downstream of the plenum (the latter presented strongly reduced oscillation amplitudes). Moreover, the stagnation temperature, measured through a classic thermocouple at the compressor inlet, proved to be an optimum parameter for surge detection, as did the electric power absorbed by the electric motor of the test rig (and thus the torque, as the rotational velocity demonstrated to be a highly stable parameter). Therefore, by observing the time series of these two parameters it is possible to clearly distinguish surge inception even with simple instrumentation (fast response thermocouples are not necessary).

- $\quad$ The surge pulsation frequency showed a slight decrease when the test was carried out at higher rotational speeds but presented higher amplitudes. This is connected with the size of the surge cycle; the larger the surge cycle is, the higher the amplitudes are, and the more the frequency decreases. This implies that deep surge pulsation has characteristics which depend not only on the type of compressor, and the piping system, but also on the compressor operating conditions. This also suggests that different degrees of deep surge could be classified depending on the pulsation characteristics, which could determine the extent of hysteresis needed in order to recover a stable condition.

By comparing the results from steady-state and dynamic tests it is clear how the piping system could affect not only the operating range, but also the type of instabilities occurring on the compressor. This agrees with many works in literature on radial and axial compressors, therefore, this study offers a valid experimental validation also for multistage centrifugal-axial compressors.

Finally, from an analysis of the signals recorded from two fast response miniature pressure transducers positioned circumferentially at the compressor inlet showed that:

- A stall cell rotating at $13 \%$ of the rotor speed was present due to the destabilizing action of the axial compressor. This cell appeared to grow in proximity to surge, while considerably reducing its amplitude during surge.

- After surge occurrence, the alternation of stall and surge was observed.

Future developments will be the use of the data collected from the characterization of the system for the identification of a dynamic model

\section{REFERENCES}

[1] Spakovszky, Z.S. Backwards Rotating Stall Waves in Centrifugal Compressors. (2004) Journal of Turbomachinery, 126(1), pp. 1-12.

[2] Cumpsty, N.A. (1989) Compressor Aerodynamics. Longman, C. 
[3] Cousins, W.T. (1996) The dynamics of Stall and Surge Behavior in Axial-Centrifugal Compressors. Ph.D. thesis, Virginia Polytechnic Institute and State University, Blacksburg, Virginia, USA.

[4] Gravdahl, J.T., Egeland, O. (1999) Compressor Surge and Rotating Stall. Modeling and Control. SpringerVerlag, London.

[5] Emmons, H., Pearson, C., Grant, H. Compressor Surge and Stall Propagation. (1955) Trans ASME 77.4: 455-469.

[6] Greitzer, E.M., Surge and Rotating Stall in Axial Flow Compressors-Part I: Theoretical Compression System Model. (1976) Journal of Engineering for Power, 98(2), pp 190-198.

[7] Greitzer, E.M., Moore, F.K., A Theory of Post-Stall Transients in Axial Compression Systems: Part IIApplication. (1986) Journal of Engineering for Gas Turbines and Power, 108(2), pp. 231-239.

[8] Gravdahl, J.T., Egeland, O. A Moore-Greitzer Axial Compressor Model with Spool Dynamics. (1997) Proceedings of the IEEE Conference on Decision and Control, 5, pp. 4714-4719.

[9] Morini, M., Pinelli, M., Venturini, M. Development of a One-Dimensional Modular Dynamic Model for the Simulation of Surge in Compression Systems. (2006) Journal of Turbomachinery, 129(3), pp. 437-447.

[10] Gravdahl, J.T., Egeland, O., Vatland, S.O. Drive Torque Actuation in Active Surge Control of Centrifugal Compressor. (2002) Automatica, 38(11), pp. 1881-1893.

[11] Strazisar, A.J., Bright, M.M., Thorp, S., Culley, D.E., Suder, K.L. Compressor Stall Control Through Endwall Recirculation. (2004) Proceedings of the ASME Turbo Expo 2004, 5 A, pp. 655-667.

[12] Morini, M., Pinelli, M., Venturini, M. Application of a One-Dimensional Modular Dynamic Model for Compressor Surge Avoidance. (2007) Proceedings of the ASME Turbo Expo 2007, 4 B, pp. 1425-1434.

[13] Kurz, R., White, R.C. Surge Avoidance in Gas Compression Systems. (2004) Journal of Turbomachinery, 126(4), pp. 501-506.

[14] Morini, M., Pinelli, M., Venturini, M. Acoustic and Vibrational Analyses on a Multi-Stage Compressor for Unstable Behavior Precursor Identification. (2007) Proceedings of the ASME Turbo Expo, 4 B, pp.14151423.

[15] Bettocchi, R., Pinelli, M., Spina, P.R. A Multistage Compressor Test Facility: Uncertainty Analysis and Preliminary Test Results. (2005) Journal of Engineering for Gas Turbines and Power, 127(1), pp. 170-177.

[16] Bettocchi, R., Morini, M., Pinelli, M., Spina, P.R., Venturini, M., Torsello, G. Setup of an Experimental Facility for the Investigation of Wet Compression on a Multistage Compressor. (2011) Journal of Engineering for Gas Turbines and Power, 133(10), doi:10.1115/1.4002947.

[17] Bulot, N., Ottavy. X., Trebinjac, I. Unsteady Pressure Measurements in a High-Speed Centrifugal Compressor. (2010) Journal of Thermal Science, 19(1), pp. 34-41.

[18] Greitzer, E.M. Surge and Rotating Stall in Axial Flow Compressors-Part II: Experimental Results and Comparison with Theory. (1976) Journal of Egineering for Power, 98(2), pp 199-211.

[19] Camp, T.R., Day, I.J. A Study of Spike and Modal Stall Phenomena in a Low-Speed Axial Compressor. (1998) Journal of Turbomachinery, 120(3), pp. 393401.

[20] Spakovszky, Z.S., Roduner, C.H. Spike and Modal Stall Inception in an Advanced Turbocharger Centrifugal Compressor. (2009) Journal of Turbomachinery, 131(3), doi:10.1115/1.2988166.

[21] Day, I. J., Freeman C. The Unstable Behavior of Low and High Speed Compressors. (1994) Journal of Turbomachinery, 116(2), pp. 194-201.

[22] Day, I.J. Stall, Surge and 75 Years of Research. (2015) Journal of Turbomachinery, 138(1), pp. 011001.

[23] Gallus, H., and Hoenen, H. Experimental Investigation of Airfoil and Endwall Boundary Layers in a Subsonic Compressor Stage, (1986) ASME Paper No. 86-GT-143.

[24] Inoue, M., Kuroumaru, M., Iwamoto, T., and Ando, Y. Detection of a Rotating Stall Precursor in Isolated Axial Flow Compressor Rotors, (1991) Journal of Turbomachinery, 113(2), pp. 281-287.

[25] Dhingra, M., Neumeier, Y., and Prasad, J. Stall and Surge Precursors in Axial Compressors, (2003) AIAA Paper No. 2003-4425.

[26] Christensen, D., Cantin, P., Gutz, D., Szucz, P., Wadia, A., Armor, J., Dhingra, M., Neumeier, Y., and Prasad, J. Development and Demonstration of a Stability Management System for Gas Turbine Engines, (2008) Journal of . Turbomachinery, 130(3), pp. 031011.

[27] Dodds, J., Vahdati, M. Rotating Stall Observations in a High Speed Compressor-Part I: Experimental Study. (2015) Journal of Turbomachinery, 137(5).

[28] Galindo, J., Tiseira, A., Arnau, F.J., Lang, R. OnEngine Measurement of Turbocharger Surge Limit. (2013) Experimental Techniques, 37(1), pp. 47-54.

[29] Galindo, J., Serrano, J.R., Guardiola, C., Cervelló, C. Surge Limit Definition in a Specific Test Bench for the Characterization of Automotive Turbochargers. (2006) Experimental Thermal and Fluid Science, 30(5), pp. 449-462.

[30] Fink, D.A., Cumpsty, N.A., Greitzer, E.M. Surge Dynamics in a Free-Spool Centrifugal Compressor System. (1992) Journal of Turbomachinery, 114(2), pp. 321-332.

[31] Liu, A.X., Zheng, X.Q. Methods of Surge Point Judgment for Compressor Experiments. (2013) Experimental Thermal and Fluid Science, 51, pp. 204- 
213.

[32] Kabalyk, K., Kryłłowicz, W., Lis'kiewicz, G., Horodko, L., and Magiera, R. Experimental Investigation of the Influence of the Inlet Duct Configuration on the Unstable Operation of a SingleStage Centrifugal Blower. (2016) Proceeding of the institution of Mechanical Engineers, Part A: Journal of Power and Energy. Doi: 10.1177/0957650915624817.

[33] Courtiade, N., Ottavy, X. Experimental Study of Surge Precursors in a High-Speed Multistage Compressor. (2013) Journal of Turbomachinery 135(6), pp. 061018.

[34] Marelli, S., Carraro, C., Marmorato, G., Zamboni, G., Capobianco. M. Experimental Analysis on the Performance of a Turbocharger Compressor in the Unstable Operating Region and Close to the Surge Limit. (2014) Experimental thermal and Fluid Science, Vol. 53, pp. 154-160.

[35] Zheng, X., Liu, A. Phenomenon and Mechanism of Two-Regime-Surge in a Centrifugal Compressor. (2015) Journal of Turbomachinery, 137(8), pp. 081007.

[36] Huang, P.X., Yin, J. Transient Surge Dynamics: A Shock Tube Theory and Experimental Comparison. (2014) Proceedings of the ASME Turbo Expo, 2 D, doi: 10.1115/GT2014-26270

[37] Mazzawy, R.S. Surge Induced Structural Loads in Gas Turbines. (1980) Journal of engineering for power, 102(1), pp. 162-168.

[38] Cargill, A. M., Freeman, C. High-Speed Compressor Surge With Application to Active Control. (1991) Journal of Turbomachinery, 113(2), pp 303-311.

[39] Day, I. Axial Compressor Performance During Surge. (1994) Journal of Propulsion and Power, 10(3), pp. 329-336. 